\title{
Nanoporous alumina membranes filled with solid acid for thin film fuel cells at intermediate temperatures
}

\author{
P. Bocchetta ${ }^{\text {a }}$, G. Chiavarotti ${ }^{\text {b }}$, R. Masi ${ }^{\text {a }}$, C. Sunseri ${ }^{\text {a }}$, F. Di Quarto ${ }^{\text {a,* }}$ \\ a Dipartimento di Ingegneria Chimica dei Processi e dei Materiali, Università di Palermo, Viale delle Scienze, 90128 Palermo, Italy \\ ${ }^{\mathrm{b}}$ Becromal S.p.A., Via E. Rosenthal 5, 20089 Rozzano - Milano, Italy
}

Received 9 June 2004; received in revised form 30 June 2004; accepted 5 July 2004

Available online 27 July 2004

\begin{abstract}
Thin film fuel cells have been fabricated by impregnation of inorganic porous membranes with inorganic proton conductor. Anodic alumina membranes $\left(50 \mu \mathrm{m}\right.$ thick and pore diameter of $200 \mathrm{~nm}$ ), filled with $\mathrm{CsHSO}_{4}$ salt have been used as protonic conductor in a hydrogen-oxygen fuel cell working between 423 and $443 \mathrm{~K}$ in dry atmosphere. Polarization curves at $433 \mathrm{~K}$ showing ohmic control with open circuit values near $0.8 \mathrm{~V}$ and short circuit current around $8 \mathrm{~mA} \mathrm{~cm}{ }^{-2}$ have been obtained. Possible causes of degradation as well as alternative routes to overcome some of the problems encountered with this approach will be reported. (C) 2004 Elsevier B.V. All rights reserved.
\end{abstract}

Keywords: Solid acid; Anodic alumina membranes; Pore filling; Thin film fuel cell; Intermediate temperature fuel cell

\section{Introduction}

Due to the high cost of polymeric membranes and poisoning effects of catalyst in presence of hydrocarbon fuel there is a large research effort aimed to exploit fuel cell assembly based on lower cost membranes and electrocatalytic materials [1]. In this frame different strategies have been suggested based on the fabrication of membranes, which could operate at higher temperatures where poisoning effects of catalysts are minimized. This choice would exclude the actual polymeric membranes employed in PEMFC, which lose their stability and good performance as proton conductor owing to dehydration effects.

It has been recently suggested that solid acids compounds like $\mathrm{CsHSO}_{4}$, undergoing a superprotonic phase transition at intermediate temperature $\left(T_{\mathrm{tr}}=414 \mathrm{~K}\right)$,

\footnotetext{
${ }^{*}$ Corresponding author. Tel.: +39-091-656-7228; fax: +39-091656-7280.

E-mail address: diquarto@mbox.unipa.it (F. Di Quarto).
}

could be used as fuel cell electrolyte in a range of temperature between 423 and $453 \mathrm{~K}$ (melting/decomposition $\mathrm{CsHSO}_{4}$ at $485 \mathrm{~K}$ ). According to this, $\mathrm{CsHSO}_{4}$ electrolyte membrane having thickness around $1.0-1.5 \mathrm{~mm}$ have been prepared and used to fabricate fuel cell working at $433 \mathrm{~K}$ able to provide open circuit cell voltage $\left(V_{\mathrm{oc}}\right)$ around $1.1 \mathrm{~V}$ and short circuit current density $\left(I_{\mathrm{sc}}\right)$ of $45 \mathrm{~mA} \mathrm{~cm}^{-2}$ [2]. The polarization curves of such fuel cell appear mainly controlled by a large ohmic drop into the solid acid membrane so that it should be possible in principle to improve the fuel cell performance by working with much thinner membranes.

In this frame we have suggested [3] the use of porous anodic alumina membranes as template for the fabrication, by filling the pores of alumina membranes with a protonic conductor, of inorganic membranes to use in fuel cell at temperatures higher than usual PEMFC. Porous alumina membranes can be electrochemically grown in a rather wide range of thickness (from few micron to hundreds micron) and porosity (from $10 \%$ to $30 \%$ ) with pores diameter ranging from 20 to $200 \mathrm{~nm}$ 
depending on anodizing parameters [4,5]. By taking into account the good thermal stability of alumina membranes in a rather wide range of temperatures our approach will make possible to prepare different MEA for different temperatures provided that a suitable electrolyte and pore filling procedure is devised.

In this work we present the preliminary results of a more systematic research aimed to exploit the possible use of porous alumina membranes as support for preparation of membrane electrode assembly (MEA) to be used in a hydrogen-oxygen fuel cell, operating in a range of temperature between 423 and $443 \mathrm{~K}$.

\section{Experimental}

Commercial (Anodisc-47 Whatman, $0.2 \mu \mathrm{m}$ ) and electrochemically grown home-prepared alumina membranes of thickness comprised between 40 and $60 \mu \mathrm{m}$ have been employed. The pore filling of as-received or initially treated membranes was performed with $\mathrm{CsHSO}_{4}$ protonic conductor synthesized from aqueous solution of $\mathrm{Cs}_{2} \mathrm{CO}_{3}$ (Aldrich, 99\%) and $\mathrm{H}_{2} \mathrm{SO}_{4}$ (Prolabo, 95\%). X-ray analysis of synthesized product was performed by a Philips X-Ray Generator (Model PW 1130) and a PW (Model 1050) goniometry. The identification was performed according to the theoretical diffraction data provided by Merinov [6] and the JCPDS experimental data available for phase II [7]. Scanning Electron Microscopy analysis of alumina membranes before and after filling procedure was performed by using a Philips XL30 ESEM Scanning Electron Microscope. DTA and TGA analysis was performed on powdered $\mathrm{CsHSO}_{4}$ by using a Netzch STA/409/2 thermal analysis equipment at a heating rate of $5{ }^{\circ} \mathrm{C} \mathrm{min}^{-1}$.

Filling procedure. Alumina membranes were filled with $\mathrm{CsHSO}_{4}$ salt according to different procedures. The results showed in this paper were obtained by simple immersion of the sample in saturated $\mathrm{CsHSO}_{4}$ aqueous solution for $15 \mathrm{~min}$. The membrane was subsequently dried by dipping in acetone for $10 \mathrm{~s}$ and exposure to air for $30 \mathrm{~s}$, for three times.

The composite membranes alumina/ $\mathrm{CsHSO}_{4}$ were finally sandwiched between two carbon paper electrodes (Toray $40 \%$ wet Proofed-E-Tek), covered with a mixture Pt black/C black (30\% Pt on Vulcan XC-72, E-Tek), stirred in $n$-butyl acetate for at least $3 \mathrm{~h}$. The catalyst loading was $1 \mathrm{mg} \mathrm{cm}^{-2}$ of black platinum. The active area was delimited by insulating silicon rubber having a square hole of $5 \mathrm{~cm}^{2}$ so that the reported current density are referred to this active area of MEA.

The MEA was assembled in a single fuel cell apparatus (Electrochem, Inc.) and fed with nitrogen (99.95\% purity, 2 bar) during the initial thermal heating period up to $433 \pm 5 \mathrm{~K}$. After reaching the chosen temperature the cell was fed with oxygen $(99.5 \%$ purity, 3 bar), and hydrogen (99.5\% purity, 1 bar) preheated at the working temperature. The cell temperature of $433 \mathrm{~K}$ was reached by a heating plate and monitored on a $\mathrm{T}$ controller (Electrochem, Inc.). The flow rates for the two gases were measured by two flowmeters (Matheson Instruments), placed before the heating bottles $\left(1.81 \mathrm{~min}^{-1}\right.$ for $\mathrm{O}_{2}$ and $2.41 \mathrm{~min}^{-1}$ for $\mathrm{H}_{2}$ ).

Polarization curves were obtained by using a PAR Potentiostat $273 \mathrm{~A}$ and HP chart recorder and acquired by computer for subsequent elaboration. A search for the presence of hydrogen sulphide in the cathodic effluent was performed by using a qualitative spot test by bubbling the effluent into $1 \mathrm{M} \mathrm{AgNO}_{3}$ aqueous solution.

\section{Results}

Salt preparation and characterization. In Fig. 1 it is reported the X-ray diffraction patterns of synthesized $\mathrm{CsHSO}_{4}$ salt employed to fill the alumina membranes. For any new preparation an X-ray diffraction pattern was obtained in order to check any difference in the $\mathrm{X}$-ray spectra related to the different synthetic routes used to prepare the salt. It is reported in literature that $\mathrm{CsHSO}_{4}$ salt can exist in three different phases depending on the temperature, with monoclinic phases II and III existing at lower temperatures and phase I, displaying an high protonic conductivity behavior, at temperature higher than $T_{\mathrm{c}}=414 \mathrm{~K}$. Although the thermodynamically stable phase at room temperature is the phase III, the metastable phase II it has been reported in the literature $[8,9]$ to exist depending on different physico-chemical parameters. In our case regardless of the synthetic route employed and different experimental conditions a mixture of different phases (II, III) in different ratios were obtained from water crystallization process. The DTA and TGA (see Fig. 2) analysis of precipitated phase displayed three phase transition with the second and third, very reproducible, transition peaks at 414 and $488 \mathrm{~K}$, respectively, and a first peak usually appearing at variable temperature ranging between 323 and $378 \mathrm{~K}$. The two reproducible peaks are attributed in agreement with literature data [9] to the II $\Rightarrow$ I phase transition $(T=414 \mathrm{~K})$ and to the phase $\mathrm{I} \Rightarrow$ liquid phase (or decomposition) transition ( $T=488 \mathrm{~K}$ ). The first transition peak (phase III $\Rightarrow$ phase II) appeared at different temperatures (Fig. 2(a) and (b)) in the range above mentioned as a function of different salt preparation variables. Such a variability is known in the literature [9] and it is reported as ambient sensitive but its origin in our samples was not investigated.

As a general trend, X-ray-analysis shows a higher concentration of phase II in the $\mathrm{CsHSO}_{4}$ preparated according to the synthetic route above described. However more intense peaks of phase III were recorded in the Xray diffraction pattern of functionalized membranes re- 

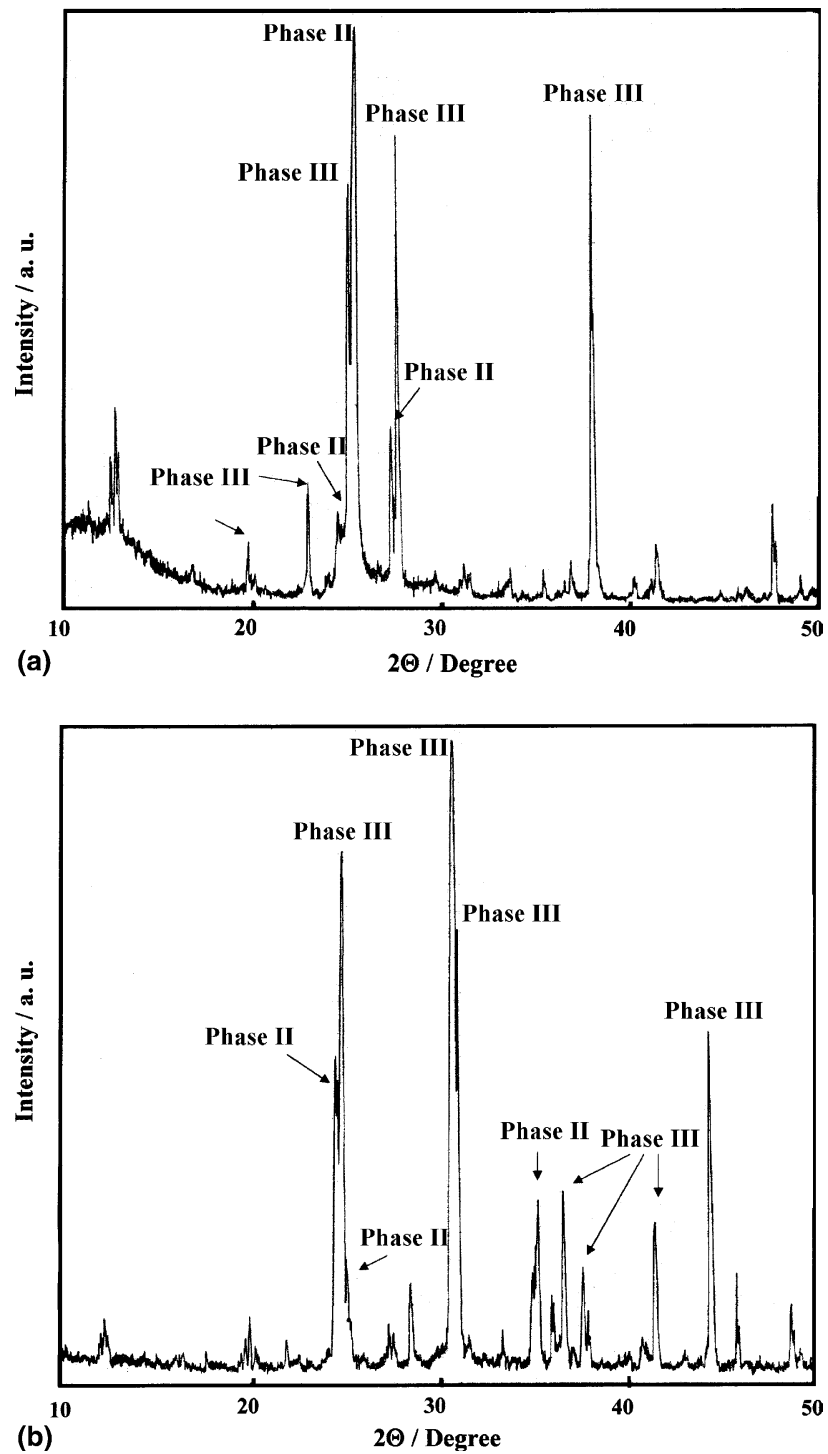

Fig. 1. X-ray diffraction pattern $(\mathrm{Cu} \mathrm{K \alpha})$ recorded at $298 \mathrm{~K}$ and $1^{\circ}$ $\mathrm{min}^{-1}$. (a) $\mathrm{CsHSO}_{4}$ precipitated as synthesized. (b) Anodic alumina membrane after pore filling with $\mathrm{CsHSO}_{4}$.

ported in Fig. 1(b). This finding could be related to the crystallization process in restricted porous sites as well as to the method followed for crystallizing the salt into the membrane.

Membranes preparation. In Fig. 3(a) and (b) we report the SEM analysis of as received commercial membranes and home prepared membranes grown in phosphoric acid solution [10] before filling with protonic conductor. The usual pores geometry previously reported in literature is visible in such figures showing cylindrical pores whose dimensions are function of the anodizing conditions [11-13]. In previous work we have shown that anodically formed alumina membranes are amorphous, as evidenced by the lack of alumina phases reflections in Fig. 1(b), and contain some small amount of incorporated electrolytic (phosphorous) species. The

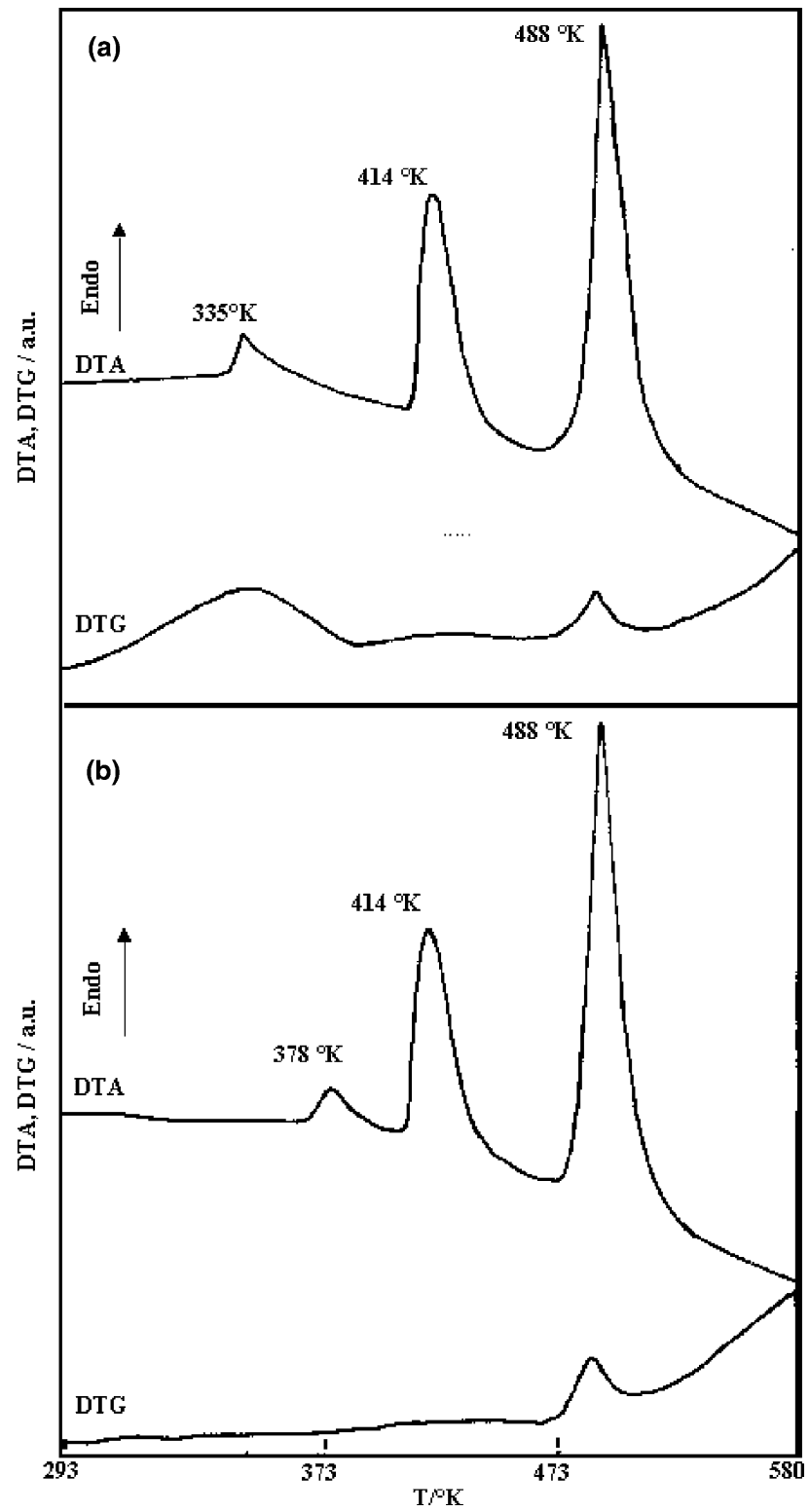

Fig. 2. DTA and DTG curves of $\mathrm{CsHSO}_{4}$ precipitated phase recorded at $5{ }^{\circ} \mathrm{C} \mathrm{min}-1$ in air. (a) As-prepared. (b) Aged in powder for 30 days.

membranes are thermally stables and start to crystallize at around $1143 \mathrm{~K}$. An estimation of porosity for alumina membranes employed in this work has been performed and an average value of about 30\% was done by assuming that all cylinders are pervious. Such a figure is in agreement with literature data [10] pertaining to electrochemically grown membranes under similar conditions.

The SEM analysis of pores structure of broken membranes before and after filling with $\mathrm{CsHSO}_{4}$ salt is also reported in Fig. 4(a) and (b) for as received industrial membranes. Analogous SEM pictures of home-prepared membranes before and after pores filling are reported in Fig. 5(a) and (b). The Fig. 5(c) shows the morphology of the same membrane after testing the fuel cell. 
(a)

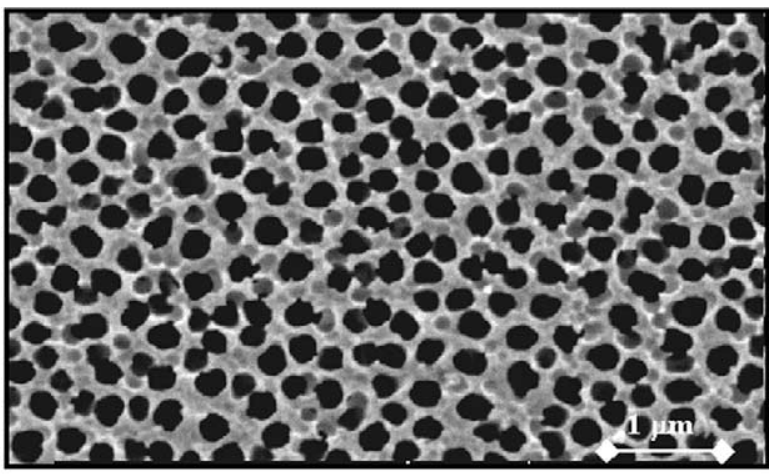

(b)

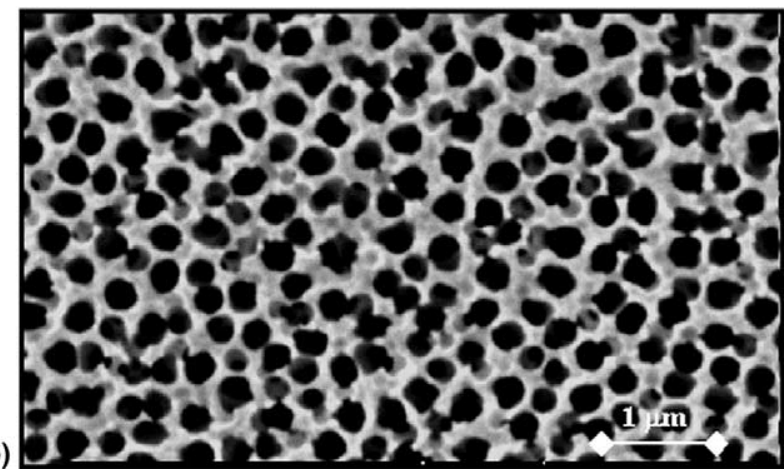

Fig. 3. SEM morphology of anodic alumina membranes surfaces before filling with protonic conductor: (a) as-received commercial membranes; (b) home-prepared membranes grown in phosphoric acid solution.

(a)

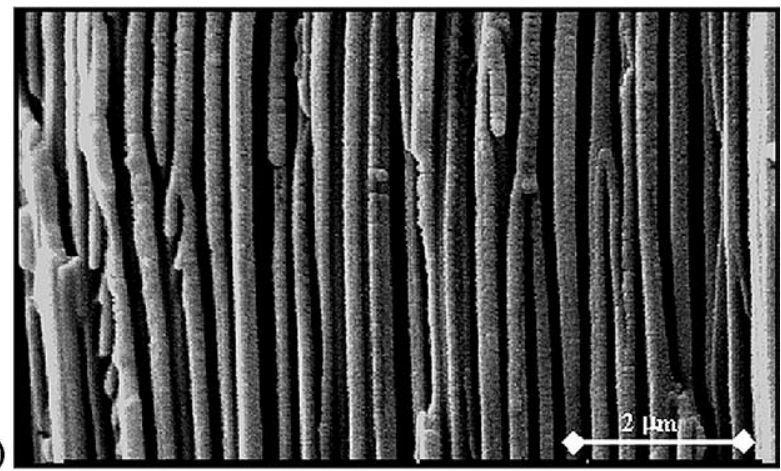

(b)

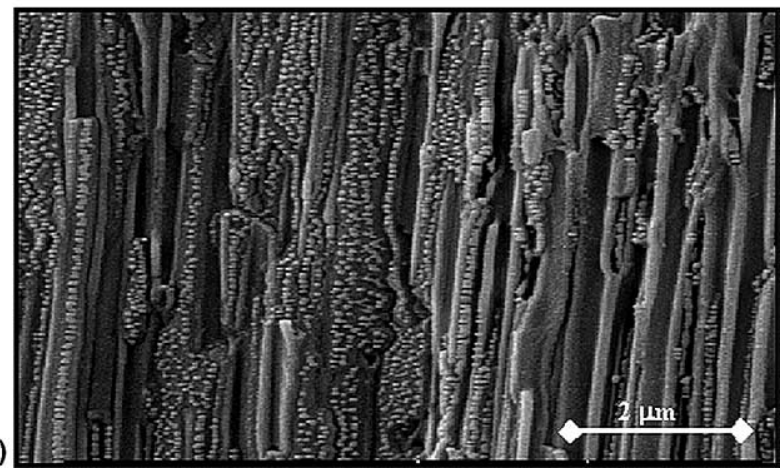

Fig. 4. SEM morphology of pores structure of broken membranes for as-received industrial anodic alumina membranes: (a) before and (b) after filling with $\mathrm{CsHSO}_{4}$ salt. (a)

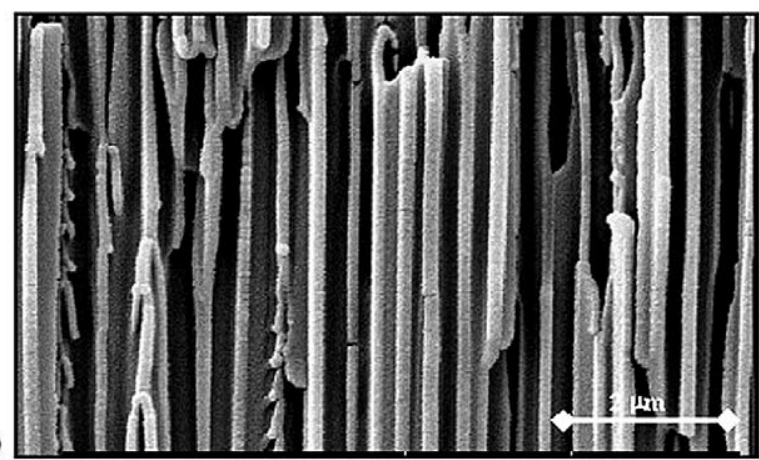

(b)

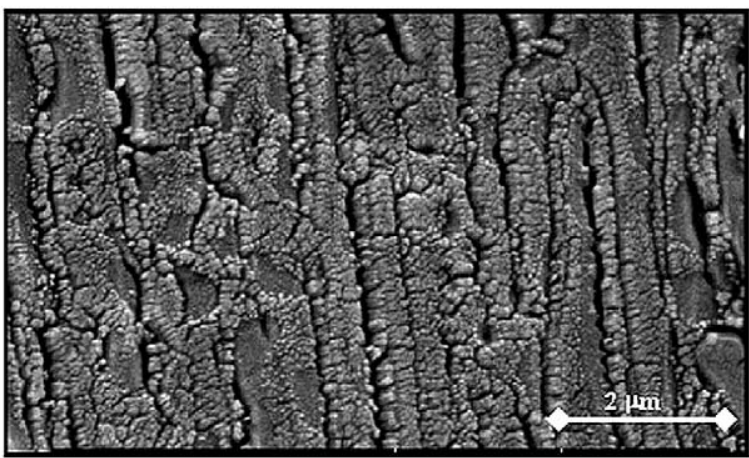

(c)

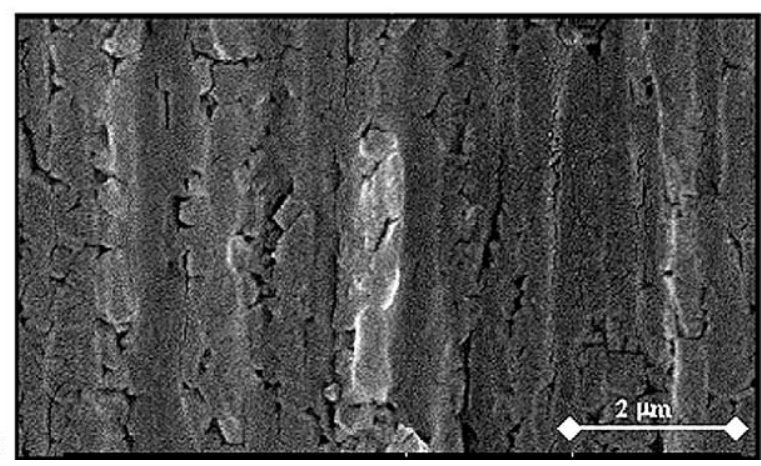

Fig. 5. SEM morphology of pores structure of broken membranes for home-prepared anodic alumina membranes: (a) before and (b) after filling with $\mathrm{CsHSO}_{4}$ salt, (c) morphology of the membrane filled with $\mathrm{CsHSO}_{4}$ after working in a $\mathrm{H}_{2} / \mathrm{O}_{2}$ fuel cell at $433 \mathrm{~K}$.

The initial treatment as well as the filling procedure affected in some way the polarization curves obtained under almost identical conditions of preparation and a problem of reproducibility of MEA assembly was encountered in spite of different filling procedure tested up to now. In the following we will present the best polarization curves, in terms of conversion efficiency, obtained representing, however, an average behavior over numerous electrodes so that they are representative of our best MEA performances.

Polarization curves. In Fig. 6(a) we report the initial polarization and output power density curves for the single fuel cell under the above reported conditions. The first polarization curve was recorded as soon after an almost constant open circuit potential $\left(V_{\text {oc }}\right)$ was reached after starting the cell feeding with gases 

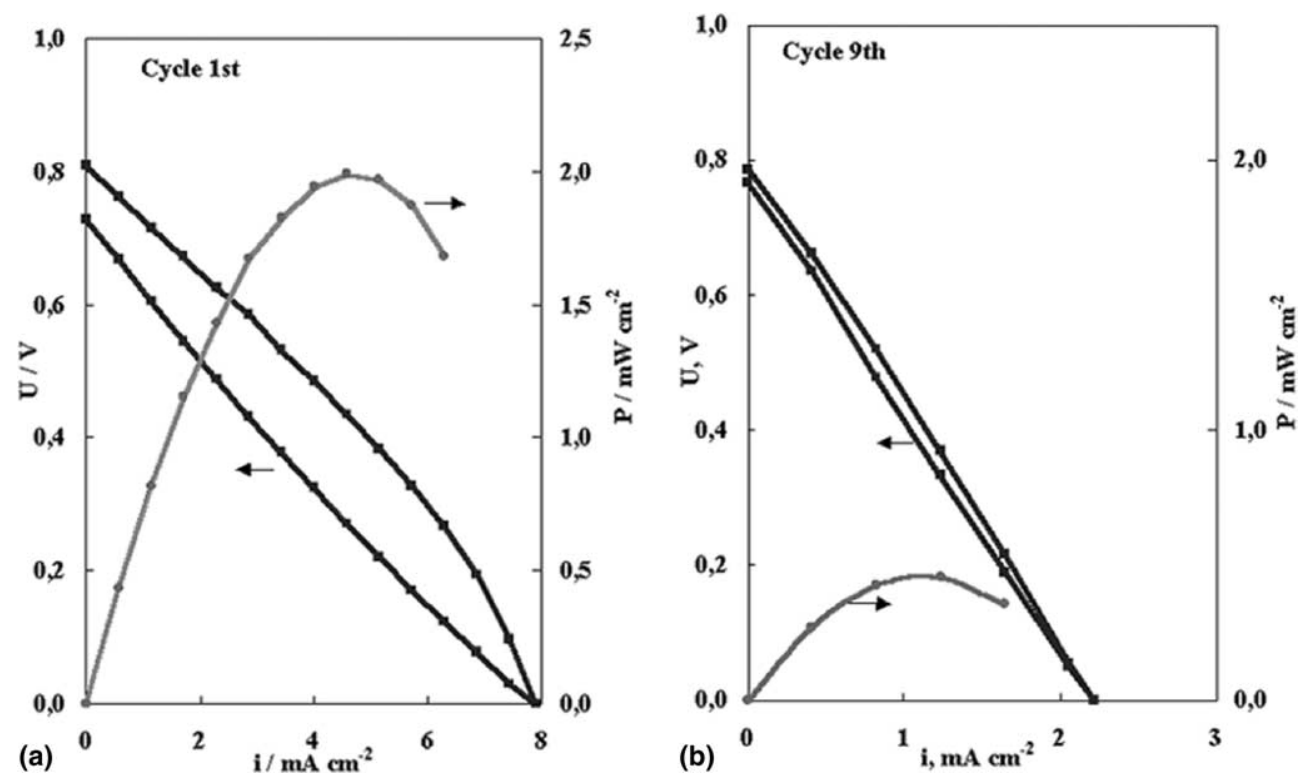

Fig. 6. Polarization curves under linear potential scan $\left(5 \mathrm{mV} \mathrm{s}^{-1}\right)$ for a $5 \mathrm{~cm}^{-2} \mathrm{H}_{2} / \mathrm{O}_{2}$ fuel cell at $433 \mathrm{~K}$ with CsHSO 4 /home-prepared anodic alumina membrane: (a) 1st cycle obtained immediately after reaching $433 \mathrm{~K}$, (b) 9 th cycle.

$\left(\mathrm{H}_{2} / \mathrm{O}_{2}\right)$. During the equilibration time the $V_{\mathrm{oc}}$ value decreased from an initial value around $1.0 \mathrm{~V}$ until the reported one, which for mostly of best MEA assemblies was around $0.8 \pm 0.05 \mathrm{~V}$. As reported in figure a large hysteresis was observed by cycling the cell from $V_{\text {oc }}$ to $V_{\text {sc }}$ (short circuit potential) when a value of current density around $8 \mathrm{~mA} \mathrm{~cm}^{-2}$ were measured for best assemblies. A peak power density of about $2 \mathrm{~mW} \mathrm{~cm}^{-2}$ was measured at the first polarization curve, but a visible and fast degradation process of cell performance was observed by continuously cycling the cell between $V_{\mathrm{oc}}$ and $V_{\mathrm{sc}}$. The degradation process affected very much the $I_{\mathrm{sc}}$ value, which for the cell of Fig. 6 changed from the initial 8 to 4.8 $\mathrm{mA} \mathrm{cm}{ }^{-2}$ after the third cycle and to $2.2 \mathrm{~mA} \mathrm{~cm}^{-2}$ after the 9th cycle (Fig. 6(b)). The $V_{\text {oc }}$ value was much less affected, changing from 0.81 to $0.73 \mathrm{~V}$, after the first cycle. Moreover the initial $V_{\mathrm{oc}}$ value could be recovered after flushing the cell with nitrogen under open circuit condition for sufficient long times but the $I_{\mathrm{sc}}$ value was not recovered after this cleaning procedure. Usually during the degradation process, due to cycling, the hysteresis of polarization curves decreased with the decrease in the $I_{\mathrm{sc}}$ value (see Fig. 6(b)). We have to mention that during the working of the fuel cell a qualitative analysis of the output gases from the anodic side evidenced in the effluent the presence of sulfide species.

\section{Discussion}

The results previously reported demonstrate that thin film inorganic composite membranes can be produced with relatively inexpensive material and by following a fabrication procedure, which allow an easy scaling to large area proton conductor membranes for intermediate temperature fuel cell. The operating temperature of membrane can be much higher than that used in this work if anodic alumina porous membranes are filled with a higher temperature proton conductor [14]. However some of the advantages related to the use of thinner membranes have not been observed in our assembly and the possible origin of such failure will be shortly discussed.

The results of Fig. 6 confirm previous findings of Haile et al. showing that the electrochemical kinetic reactions within the fuel cell are under ohmic control owing to the large resistance of alumina membranes containing $\mathrm{CsHSO}_{4}$ salt. However by correcting the data of Haile et al. for the average estimated porosity $(30 \%)$ and thickness of anodic alumina membrane $(50 \mu \mathrm{m})$ it comes out that our best $I_{\mathrm{sc}}\left(8 \mathrm{~mA} \mathrm{~cm}{ }^{-2}\right)$ values are far from that ones $\left(300 \mathrm{~mA} \mathrm{~cm}^{-2}\right)$ expected by scaling the data in [2] under the hypothesis of pure ohmic control. We have to mention that, apart the differences in the MEA assembly, the main change in our case was the Pt loading (1 $\mathrm{mg} \mathrm{cm}^{-2}$ against $18 \mathrm{mg} \mathrm{cm}^{-2}$ in [2]). To raise at such high Pt loading in MEA assembly was rather difficult in our configuration owing to the fragility of thin alumina membranes.

However a second aspect to mention was the fact that a poisoning of the catalyst owing to the formation of $\mathrm{PtS}$ or $\mathrm{PtS}_{2}$ species on the surface electrode at the anode was occurring during the working period of fuel cell. The formation of $\mathrm{H}_{2} \mathrm{~S}$ at anode at high temperature and in presence of platinum catalyst has been suggested according to equation 
$2 \mathrm{CsHSO}_{4}+4 \mathrm{H}_{2} \rightarrow \mathrm{Cs}_{2} \mathrm{SO}_{4}+4 \mathrm{H}_{2} \mathrm{O}+\mathrm{H}_{2} \mathrm{~S}$

in [15] and qualitatively tested in our experiments by flushing the anodic effluent into an $\mathrm{AgNO}_{3}$ aqueous solution. The presence of $\mathrm{H}_{2} \mathrm{~S}$ in the effluent was already visible near the open circuit condition after a very small amount of electric charge was circulated in the cell. Our observation agrees with the suggestion of Haile et al. [15] that a transformation of sulphate acid to sulphate with contemporary production of hydrogen sulphide occurs at the catalyst/electrolyte interface during the current circulation. Such a transformation from ionic conducting $\mathrm{CsHSO}_{4}$ to insulating $\mathrm{Cs}_{2} \mathrm{SO}_{4}$ could account for the large hysteresis in the first polarization curves. The possible crossover of $\mathrm{H}_{2} / \mathrm{O}_{2}$, trough not perfectly sealed pores, cannot be excluded apart the poisoning of catalyst, owing to the fact that $V_{\text {oc }}$ values always less than $1.0 \mathrm{~V}$, also under transient conditions, were measured in our cell.

\section{Conclusions}

At variance with previous results on porous glass [16] it has been shown, for the first time as far as we know [3], that thin film alumina membranes can be used as template for ionic conductor membrane allowing to fabricate different assemblies to be used in different types of fuel cell. The easy preparation of alumina membranes also in large area, their low production cost and wide range of thermal stability could make them attractive for more economically viable fuel cell by allowing to increase the working temperature of the fuel cell and the use of less expensive catalyst. In front of such advantage some unsolved problems like: filling of pores with ionic conductor species, choice of catalyst, mechanical fragility of anodic alumina membranes, are still a challenge for electrochemical materials scientists.

\section{Acknowledgements}

Some of the authors (P.B. and R.M.) like to thank BECROMAL SPA for providing a financial support. This work has been partially founded by Palermo University through a fellowship to Dr. P. Bocchetta.

\section{References}

[1] S.M. Haile, Acta Materialia 51 (2003) 5981.

[2] S.M. Haile, D.A. Boysen, C.R.I. Chisholm, R.B. Merle, Nature 410 (2001) 910.

[3] G.P. Chiavarotti, C. Sunseri, U. Gullo, F. Di Quarto, P. Bocchetta, European Patent Application (2003) EP 1357626 A1 and (2004) EP 1391235 A2.

[4] P. Bocchetta, C. Sunseri, A. Bottino, G. Capannelli, G. Chiavarotti, S. Piazza, F. Di Quarto, Journal of Applied Electrochemistry 32 (2002) 977 and references therein.

[5] P. Bocchetta, C. Sunseri, R. Masi, S. Piazza, F. Di Quarto, Material Science and Engineering C23 (2003) 1021 and references therein.

[6] Materials And Process Simulation Center - Caltech MC 139-74 1200 E. California Blvd, Pasadena, CA 911253.

[7] JCPDS International Centre for Diffraction Data - Card No. 471724.

[8] M. Friesel, A. Lundén, B. Baranowski, Solid State Ionics 35 (1989) 91.

[9] A.V. Belushkin, C.J. Carlile, L.A. Shuvalov, Condensed Matter 4 (1992) 389

[10] P. Bocchetta, C. Sunseri, G. Chiavarotti, F. Di Quarto, Electrochimica Acta 48 (2003) 3175.

[11] J.W. Diggle, T.C. Downie, C.W. Goulding, Chemical Review 69 (1969) 370.

[12] A.P. Li, F. Muller, U. Gosele, Electrochemical and Solid-State Letters 131 (2000) 3.

[13] G. Patermarakis, N. Papandreadis, Electrochimica Acta 38 (1993) 2351.

[14] D.A. Boysen, T. Uda, C.R.I. Chisholm, S.M. Haile, Science 303 (2004) 68.

[15] R.B. Merle, C.R.I. Chisholm, D.A. Boysen, S.M. Haile, Energy and Fuels 17 (2003) 210.

[16] C. Yang, P. Costamagna, S. Srinivasan, J. Benziger, A.B. Bocarsly, Journal of Power Source 103 (2001) 1. 